\title{
IPMA"。
}

\section{WE ARE ALL GOING TO BUILD THE FUTURE: A MESSAGE FROM THE IPMA PRESIDENT}

\author{
Jesus Martinez Almela \\ International Project Management Association
}

\section{Everyone at home and designing the tomorrow that we all need}

The world has been locked down for the last months in certain countries. In the last weeks, life in many countries is coming to a standstill due to an unexpected black swan - called SARS-CoV-2. This is a virus from the coronavirus family causing the COVID-19 disease, now recognised as a pandemic. But is the virus really new? Or is it a black swan caused by the fact that experts and people in charge have not applied lessons learned from situations generated by other, recent outbreaks of similar viruses. Our brain, the human brain, tends to quickly forget unpleasant, chaotic and painful situations and circumstances as a response mechanism. And the response is usually forgetfulness, as well as a lack of applying lessons learnt. Those who know me personally also know that my thirty-plus years of professional experience has been connected with the rural world and the agri-food sector. It is clear that most of the recent epidemics and pandemics have been generated here.

What makes this pandemic different from other ones? It must be because we did not want to recognize and investigate this known risk further. The risk was always there. And available in a global world where information (true and fake) is transmitted practically in real-time. Assimilating this information is not an easy task for many people, especially in uncertain times. The lessons learned applied from the last "flu-like" epidemics, not to mention other epidemics, were only a few. Most governments around the world reacted late and even badly, at least at the wrong time.
For these types of latent risks, we need a common strategy, a portfolio that defines priorities and programmes that align the projects necessary to address the challenges. This was not done. See the link with Bill Gates talking about the pandemic (TED Talk).

In past weeks, an enormous amount of information has been written, published and shared in all kinds of media. News about the polyhedral form of the virus, its origins, history, trends, impact and what it will generate. A positive aspect of all of this is that this arouses curiosity and many people want more and better knowledge about the pandemic and how it is (and will in the future) impact our societies. Without any doubt, the world we thought we knew a couple of days ago will not necessarily be different - when the curve flattens and we all return to "relative" normality.

It is inevitable nowadays to read and hear statements such as: "We are facing a war without conventional weapons". But this is a war in which battles are fought on different fronts. And by different actors. At this time they are the dedicated doctors, nurses people from other emergency services and the security forces that ensure the basic needs of the local population. They are the actors who simply sacrifice themselves the most, so the rest of the citizens (many of them confined in their houses voluntarily and/or obligatory) can support the front against the enemy - COVID19.

But the rest of us cannot sit still. Especially those who must continue working in their

This article is downloaded from the site https://www.ipma.world/we-are-all-going-to-build-the-future-amessage-from-the-ipma-president/

ISSN 2560-4961 (online)

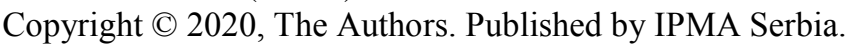

This is an open access article under the CC BY-NC 4.0 license (https://creativecommons.org/licenses/bync/4.0/)

doi: $10.18485 /$ epmj.2020.10.1.1 
fields, and for sure those remotely working from their homes. More than ever we need to understand the importance of transcending projects, programmes and portfolios and the competences needed for these. The time will come for further reflection about the lessons not learned this time. Now is the time for solidarity and teamwork.

We cannot leave our politicians, our institutions, our companies and other responsible groups alone. Now is the time when we must evangelize more than ever about the advantages of our profession. A profession whose success is based on personal and social skills (people-focused), context understanding (perspective focused) and technical skills (practice focused). For this, we need a common strategy, more and better projects, programmes and portfolios. And above all, we need more competent directors/managers of these projects, programmes and portfolios.

\section{We, at the International Project} Management Association (IPMA), currently with 73 national Member Associations worldwide, are going to do it. We are the oldest network for the project management profession worldwide, being active for more than 55 years. We represent a professional network that promotes excellence in projects, programmes and portfolios, supporting the development of individual, organisational and project management competences.

IPMA has global standards in place that define all of these. All these competences are needed at this difficult time. A time where regional and local networks must collaborate more closely, addressing the specific challenges of the region or local environment. Minimising the impact of the crisis.

All of us today must be more disciplined and rigorous than ever. In our respective fields as professionals and individuals, we must protect others by protecting ourselves. This asks us to prioritise others above ourselves and is a completely new "state of war" that we must win together by contributing facts, not fiction, reality instead of falsehoods and simply by doing the right things. One day at a time.

It is time to show that we are what we say at IPMA: proud to be part of the IPMA Family, a family of professionals who build relationships for life, far beyond institutional relationships. Ready to tackle difficult challenges of the future.

The COVID-19 crisis will provoke both ideological and economic earthquakes: we are moving towards a new horizon. We need to begin to build just now, at this very moment, with the social, economic and political measures taken to solve this global crisis in each country and region. Hiding out and thinking that "it will clear itself soon" or "that everything can be solved with individual responsibility and self-discipline only" may not be the right approach for many individuals. But now, even more than ever, programme and project management, and portfolio direction are more necessary to be implemented. Naturally, by competent project managers. A new global scenario and "a new world" is coming, and we cannot ignore it. We are here - 73 nations, to help in this process and to do it in a sustainable manner.

The IPMA Executive Board is working on different scenarios to contribute to mentioned challenges:

- We have started with activities aimed at digitalizing the requirements of the different professional certification schemes. We'll be sharing more information about it in the forthcoming days and weeks.

- We have extended deadlines for applications to the global Project Excellence and Individual Awards, validations etc.

- We will proceed with our online activities and also increase the level and content of our communication.

- We have cancelled the events that were planned in March up to June. We will be updating our programme of national, regional and global events soon.

The most important thing at the moment is to take care of your and our physical and mental health. With the same objective: to win this battle against COVID-19 and build the desired, common future. We can only do this together. We will continue as IPMA to focus on developing competent professionals, 
committed and used to sharing valuable insights for our common good. Just as we have done for more than half a century now.

For all Member Associations (MA) I would like to stress that there are KAMM's avalilable to assist and help with any issues that you have. We will support each MA in coordinating the necessary actions in the different remits: certification, professional development, education, GIS, research, events, etc. Please do not hesitate to contact them.
In the next few days, we'll be informing you about a series of webinars that we are planning to organise. We will also share some additional information with respect to the cancelled the Kathmandu $\mathrm{CoD}$ a few weeks ago.

I am convinced that together we will help to build a better and more sustainable and common future. Right now I kindly ask you all to stay at home, protect yourselves and your loved ones. For those who have no other option, please take all the necessary precautions advised. 